\section{O JOGO DIGITAL “ASSASSIN'S CREED ORIGINS” COMO UM ESPAÇO DE DECOLONIZAÇÃO DA CIÊNCIA: uma análise do modo turismo à luz do entendimento de química ancestral africana}

\author{
THE DIGITAL GAME "ASSASSIN'S CREED ORIGINS" AS A SPACE FOR THE DESOLONIZATION \\ OF SCIENCE: an analysis of the tourism mode in the light of the understanding of \\ African ancestral chemistry
}

\author{
EL JUEGO DIGITAL "ASSASSIN'S CREED ORIGINS" COMO UM ESPACIO PARA \\ LA DECOLONIZACIÓN DE LA CIÊNCIA: un análisis del modo turismo a la luz de \\ la comprensión de la química ancestral africana
}

\section{AUTORES:}

ROBERTO DALMO VARALLO LIMA DE OLIVEIRA

ORCID 0000-0002-8348-966X

'Universidade Federal do Paraná (UFPR)

VINÍCIUS GURSKI FERRAZ

ORCID 0000-0003-0421-5810

${ }^{2}$ Universidade Federal do Paraná (UFPR)

JOÃO ROBERTO RATIS TENÓRIO DA SILVA 3

ORCID 0000-0002-6479-2081

Resumo: À luz dos estudos e movimentos de decolonização dos saberes, em específico, do entendimento de Química Ancestral Africana como ressignificação das "artes práticas”, o presente trabalho buscou investigar a seguinte questão: o jogo Assassin's Creed Origins, em seu modo turismo, apresenta um conteúdo sobre Ciência Química que destaque matrizes epistêmicas não europeias? Foi realizada uma pesquisa qualitativa de caráter documental que, utilizando-se da análise de conteúdo, possibilitou o surgimento da categoria "Conhecimentos, métodos e técnicas desenvolvidas no Egito" e das subcategorias 1 - Desenvolvimentos medicinais e cosméticos; 2 - Bebidas, alimentos e fabricação de produtos cotidianos; 3 - mumificação. As subcategorias nos ajudam a compreender que o artefato cultural selecionado contribui para entendermos o Egito como produtor de conhecimento químico, destacando que diversos processos como Epistemicídios e Pilhagens epistêmicas usurparam da África o direito a esse reconhecimento colocando-a em um espaço no qual as referências remontam exclusivamente a escravidão. O Egito retratado como um lugar de potência científica é uma questão de justiça epistêmica e pode contribuir tanto para processos de ensino e aprendizagem quanto para a divulgação de uma ciência não eurocentrada.

Palavras-Chave: jogos digitais; decolonialidades; química ancestral africana.

Abstract: Based on studies and movements of decolonization of knowledge, in particular, the understanding of African Ancestral Chemistry as a resignification of "practical arts", the present paper sought to investigate the following question: does the game Assassin's Creed Origins, in the Discovery Tour, presents a Chemical Science content that emphasizes non-European epistemic matrices? A qualitative documental research was carried out which, using content analysis, enabled the emergence of the category "Knowledge, methods and techniques developed in Egypt" and of the subcategories 1 - Medicinal and cosmetic developments; 2 Beverages, food and manufacture of everyday products; 3 - mummification. The subcategories helped us to understand that the selected cultural artifact contributes to understanding Egypt as a producer of chemical knowledge, highlighting that several processes such as Epistemicides and Epistemic Plundering have usurped Africa's right to this recognition, placing it in a space in which the references date exclusively slavery. The Egypt portrayed as a place of scientific power is a matter of epistemic justice and can contribute both to teaching and learning processes and to the dissemination of a non-Eurocentric science.

Keywords: digital games; decoloniality; African ancestral chemistry.

Resumen: A la luz de los estudios y movimientos de decolonización del conocimiento, específicamente, la comprensión de la Química Ancestral Africana como una resignificación de las "artes prácticas", el presente trabajo buscó investigar la siguiente pregunta: ¿el juego Assassin's Creed Origins, en su modalidad turística, presenta un contenido de ciencia química que enfatiza las matrices epistémicas no europeas? Se realizó una investigación cualitativa de carácter documental que, mediante el análisis de contenido, permitió el surgimiento de la categoría "Conocimientos, métodos y técnicas desarrollados en Egipto" y de las subcategorías 1- Desarrollos medicinales y cosméticos; 2 - Bebidas, alimentos y fabricación de productos de uso diario; 3 - mumificación. Las subcategorías nos ayudan a comprender que el artefacto cultural seleccionado contribuye a entender a Egipto como productor de conocimiento, destacando que varios procesos como los Epistemicidios y los Saqueos Epistémicos han usurpado el derecho de África a este reconocimiento, ubicándolo en un espacio en el que las referencias se refieren exclusivamente a uno esclavitud. Egipto retratado como un lugar de ciencia y una cuestión de justicia epistémica y puede contribuir tanto a los procesos de enseñanza y aprendizaje como a la difusión de una ciencia no eurocéntrica Palabras clave: juegos digitales; decolonialidades; química ancestral africana.
Universidade Federal de Pernambuco (UFPE)

MAYARA SOARES DE MELO

ORCID 0000-0002-1494-9183

${ }^{4}$ Universidade Federal do Oeste da Bahia (UFOB)

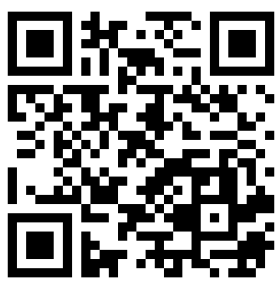

Para citar este artigo:

OLIVEIRA, R. D. V. L.; et al. O jogo digital "assassin's creed origins" como um espaço de decolonização da ciência: uma análise do modo turismo à luz do entendimento de química ancestral africana. Revista Eletrônica Ludus Scientiae, 14-27, 2020. 


\section{INTRODUÇÃO}

Karl Jaspers, médico e filósofo, afirma que a ciência moderna seria um fenômeno que não possuiria equivalente em toda história da humanidade: ela é peculiar ao Ocidente. A China e a Índia, dela, conheceram apenas algumas noções iniciais e imprecisas; por outro lado, devemos à Grécia um sem-número de ideias geniais (JASPERS, 1989, p.104). Tal consideração, feita em 1960, em comemoração aos 500 anos da Universidade da Basiléia - Suíça -, retrata um fragmento da representação sobre a Ciência construída ao longo de séculos. Ciência essa que surgiu, segundo Pinheiro e Rosa (2018), a partir do impulsionamento da base produtiva no sistema capitalista e a reboque de outras formas de conhecimento silenciadas, apagadas, usurpadas.

Processos hoje conceituados como pilhagem epistêmica e epistemicídio são fundantes da ciência moderna e, como reflexo, percebemos discursos como o de Jaspers, atribuindo o conhecimento científico moderno à Grécia, negando o Oriente e nem se lembrando de citar o continente africano. Pinheiro e Rosa (2018) destacam que as representações de cientistas reproduzem a noção do poder europeu sobre o mundo na forma de homens cisgêneros, heterossexuais e brancos, assim, todos que estavam fora desses padrões eram rechaçados, inferiorizados e silenciados. Dando destaque aos processos citados anteriormente, Pinheiro e Oliveira (2019) fazem uma reflexão sobre a divulgação científica:

Divulgar qual ciência? É a questão central que aqui se coloca, não numa perspectiva relativista, mas tão pouco sob uma ótica universalista do conhecimento europeu. Entretanto, a partir de um resgate histórico que valorize os conhecimentos clássicos construídos e apropriados dentro de outras cosmovisões de mundo (PINHEIRO; OLIVEIRA, 2019, p. 8).

Outro aspecto relevante dá-se no destaque feito por Oliveira e Silva (2019) sobre a importância dos Jogos digitais, entendidos como obras de arte e com potencial para possibilitar discussões sobre ciência e Direitos Humanos, além de ser um artefato cultural com grande potencial para a divulgação da ciência em diversos dos seus aspectos, discutidos posteriormente nesse texto.

Sendo assim, tendo em vista 1) a necessidade de pensarmos e construirmos divulgação científica que extrapolam uma matriz epistêmica europeia e que possam engendrar discussões de processos como pilhagem epistêmica e epistemicídio; 2) a possibilidade dos jogos digitais, entendidos como obras de arte, contribuírem com a divulgação científica, o presente artigo apresenta uma pesquisa que buscou investigar a seguinte questão: o jogo Assassin's Creed Origins, em seu modo turismo, apresenta um conteúdo sobre Ciência Química que enfatize matrizes epistêmicas não europeias? Assim, nosso objetivo foi analisar o conteúdo textual do jogo Assassin's Creed Origins (ACO), evidenciando o discurso de/sobre ciência da natureza existente no Modo Turismo do Jogo. A escolha do jogo foi motivada por entendermos que ele dialoga com os critérios estabelecidos por Oliveira e Silva (2019) - a interface entre jogos como arte, possibilidades de discussões sobre ciências da natureza, bem como as possibilidades de humanizá-la. Em especial, destacamos o modo turismo por considerá-lo um repositório de conhecimentos sobre o Egito em diversos âmbitos como, por exemplo, história, arquitetura, ciências, etc. Além disso, esse modo apresenta diversos conhecimentos de forma condensada, tornando-se de mais fácil utilização em ambientes formais de aprendizado. ${ }^{1}$

Para tal, construímos uma pesquisa de natureza empírica, qualitativa, de caráter documental, baseada na análise de conteúdo do modo turismo do jogo ACO. Na primeira seção apresentamos nosso entendimento sobre jogos digitais como artefatos culturais permeados por valores, a sua importância para divulgação científica e a necessidade de uma divulgação que estabeleça diálogos com ciências de matrizes não europeias. Na segunda seção abordaremos o jogo Assassin's Creed Origins tanto no que diz respeito ao seu enredo, personagens e Gameplay quanto em relação ao modo turismo - foco de nosso estudo. Na terceira seção destacamos a metodologia empregada com intuito de responder

'É importante destacar que o fato de considerarmos o modo turismo de Assassin's Creed Origins mais acessível no que diz respeito à capacidade de diálogo com diversos membros de comunidades educacionais - família, coordenação pedagógica, etc. -, não descartamos a relevância do modo jogo, inclusive tais pesquisas estão no escopo de trabalhos futuros. 
nossos questionamentos iniciais. Em seguida trazemos um pouco dos resultados e discussões e algumas considerações finais.

\section{JOGOS DIGITAIS E EPISTEMOLOGIAS EMERGENTES}

Os jogos digitais, como formas de entretenimento, surgem a partir do jogo Tennis for Two. Seu desenvolvimento, no ano de 1958, pelo físico norte-americano William Higinbotham, no Brookhaven National Laboratory, é considerado como um marco de uma indústria bilionária - ainda em ascensão. Segundo Costikyan (2002) os jogos são formas de arte e os (as) Game Designers são os(as) artistas que poderão despertar diversas sensações prazerosas nos(as) jogadores(as) a partir de elementos sensoriais, de fantasia, narrativa, desafio, sensação de comunidade, descoberta, entre outros. Com um destaque para a narrativa, Dubiela e Battaiola (2007) reforçam que é preciso um esforço de investigação no que tange a influência de narrativas de videogame na cognição dos jogadores, uma vez que os jogos possuem uma potência no que diz respeito à apresentação das histórias, assim como o cinema. Kellner (2001) destaca que a mídia é um espaço de disputas culturais e, de maneira direta ou indireta, ressoa questões relevantes pela sociedade contemporânea. Cleophas, Cavalcanti e Soares (2018) consideram que os jogos podem ser entendidos como educativos informais de acordo com a intencionalidade pedagógica. Entretanto, também destacamos que, para além desses conceitos como significados fixos, entendemos que a intencionalidade pedagógica deve ser sempre acompanhada do questionamento sobre "o que" os desenvolvedores do jogo buscavam ensinar.

Assim, um jogo pode ser considerado educativo informal no âmbito de conceitos científicos, mas educativo formal no âmbito de valores específicos - como cooperação, por exemplo. Consideramos que o jogo Assassin's Creed Origins não possui intencionalidade pedagógica no que se refere especificamente à ciência Química ou a uma visão de mundo amparada em decolonialidades, podendo ser considerado um jogo educativo informal, porém, no âmbito do modo turismo, como os desenvolvedores revelam em um vídeo oficial "No Discovery tour queremos que a experiência se concentre nos atos de aprender e descobrir". Os desenvolvedores falam que a ideia de criação de um "modo turismo" surge a partir do contato de professores (as) com a empresa Ubisoft e um pedido constante de que fossem elaborados materiais baseados em Assassin's Creed para a utilização em salas de aula. Sendo assim, o modo turismo pode ser considerado um jogo educativo formal e informal, hibridizando conceitos, em um mesmo disco compacto.

Em Oliveira e Silva (2019) foi defendido que jogos digitais podem potencializar discussões que estão na interface entre Educação Científica e Educação em Direitos Humanos. A partir de um entendimento do jogo como arte, deu-se ênfase nas percepções de que os jogos digitais podem tangenciar questões sensíveis à humanidade, proporcionar experiências estéticas, reestruturar conceitos sobre arte e serem recursos da expressão criativa. Assim, abre-se a possibilidade de proporcionar o entendimento dos jogos como um fazer político (RANCIERE, 2005), no provocar interações interculturais críticas (RICHTER, 2010), possibilitar reflexões sobre conceitos como cultura, identidade cultural, alteridade, universalidade e regionalismo. Além disso, colocar em contraste as igualdades e as diferenças, problematizando as relações de poder e comparando-as com "verdades" pré-estabelecidas (SILVA e ARAÚJO, 2007).

Em consonância, podemos também destacar a relevância dos jogos digitais no que diz respeito à formação de valores. Flanagan e Nissenbaum (2016) nos dizem que todos os jogos expressam e incorporam valores humanos - tanto no âmbito da justiça quanto no que se refere a condições humanas, proporcionando um espaço para que as pessoas expressem suas crenças e ideias. Values at Play reflete sobre valores socialmente reconhecidos como justiça, igualdade, liberdade, autonomia, segurança, felicidade, privacidade, tolerância, cooperação, criatividade, generosidade, confiança, equidade, diversidade, fidelidade, integridade, ambientalismo, liberação, autodeterminação, democracia e tradição (FLANAGAN; NISSENBAUM, 2016, p. 22). Reforçamos a importância de enfatizar jogos que promovam determinado valores em detrimento de outros. Flanagan (2009) nos apresenta o conceito de Critical Play como um ato político de ocupação de espaços lúdicos e demais 
atividades que representariam os aspectos da vida humana. Nesse exame cuidadoso dos temas sociais, culturais, políticos ou pessoais que interpelam tanto a existência dos jogos quando o ato de jogar fazemos constantes escolhas e, para nossos objetivos, por exemplo, enfatizamos jogos que promovam os valores antirracistas e tentamos rechaçar jogos que reforcem discursos e estereótipos racistas; enfatizamos aqueles que promovam valores de equidade de gênero e rechaçamos os que reforçam valores de desigualdade de gênero. Jogar é não somente um ato político, como uma ação constituinte de nossas identidades. Os jogos são formas de arte que expressam valores em elementos que vão desde a premissa narrativa, personagens, regras, ao engine e softwares utilizados para seu desenvolvimento. São eles, então, artefatos culturais que poderão possibilitar tanto a aprendizagem quanto a divulgação da ciência e contribuir para a formação de valores em diálogo com a cultura dos direitos humanos.

Sendo assim, devemos nos questionar sobre qual ciência é representada pelos jogos, além do "como" tal divulgação é feita. Em destaque para este trabalho, indagamos sobre como a ciência Química estaria presente no modo turismo do jogo Assassin's Creed Origins. Esse questionamento é válido uma vez que, para Grosfoguel (2007), a epistemologia eurocêntrica ocidental dominante não admite nenhuma outra epistemologia como espaço de produção de pensamento crítico nem científico. Mignolo (2003) reforça que a narrativa de desenvolvimento e progresso da modernidade europeia se construiu a partir de outras narrativas silenciadas, de forma que o eurocentrismo poderia ser considerado uma autoproclamação, baseada na negação de outras formas de racionalidade.

A filosofia cartesiana assume a epistemologia do ponto zero, ou seja, um ponto de vista
que não assume a si mesmo como ponto de vista. (...) Qualquer conhecimento que
pretenda partir do corpo político do conhecimento (ANZALDÚA, 1987; FANON, 2010)
e chegar à geopolítica do conhecimento (DUSSEL, 1977), em oposição ao mito do
conhecimento da egopolítica cartesiana, é visto como tendencioso, inválido,
irrelevante, sem seriedade, parcial, isto é, como conhecimento inferior
(GROSFOGUEL, 2016, p.30).

Diante de tal cenário, reforçamos a relevância de artefatos culturais, tanto no âmbito da educação formal quanto da divulgação científica, que promovam a coexistência entre saberes indígenas, quilombolas e africanos. Esses entendidos também como ciência e não como uma pseudociência e que foram apagados por disputas geopolíticas e não por sua irrelevância. Como destaca Maldonado-Torres (2017), a colonialidade desconfigura-se em um padrão de poder que surge com o colonialismo, porém, ao invés de manter-se apenas na relação formal de poder entre os povos ou nações, ele amplia sua gama de domínios a partir de padrões que afetam dimensões intersubjetivas - articulados entre si através do capitalismo e da ideia de raça. Assim, apesar de o colonialismo preceder, a colonialidade sobrevive ao colonialismo (MALDONADO-TORRES, 2017). Sendo assim, os estudos sobre colonialidade entendem que esse processo intersubjetivo dá-se: 1 ) a partir de dimensões de como a colonialidade do poder (QUIJANO, 2005) demarcada a partir de uma classificação racial e desumanização do outro não-europeu; 2) da colonialidade do saber (LANDER, 2005) que seleciona quais conhecimentos devem ser reconhecidos como científicos e válidos em detrimento de outros; e 3) da colonialidade do ser (MIGNOLO, 2003); (MALDONADO-TORRES, 2017) que subalterniza e desumaniza o outro em consequência da invisibilidade do poder e do saber. Como destacam Oliveira e Salgado (2020), essas expressões de colonialidade estão associadas à violência colonial - processo de genocídio, epistemicídio e espoliação ao qual foram submetidos os povos e a natureza dos territórios colonizados.

Diante do padrão imposto a nós pela colonialidade, surge a necessidade de uma desobediência epistêmica (MIGNOLO, 2008) e, como destacam Oliveira e Salgado (2020), é preciso pensar a partir das margens, isto é, da periferia global. Sendo assim, o pensamento decolonial não se trata se uma desqualificação do pensamento científico fundamentado em bases europeias, mas uma tentativa de evidenciar relações de poder fundante da ciência moderna. Miranda (2013) reforça que há uma insuficiente efetivação de uma educação que combata matrizes coloniais de poder. A autora também 
destaca a importância de espaços não-formais de aprendizagem como ambientes promotoras de novas cartografias, uma vez que possuem maiores condições para uma recomposição epistêmica.

Como enfatizaremos a seguir, o jogo Assassin's Creed Origins possui como foco uma narrativa ambientada no Egito. Silva e Pinheiro (2018) destacam que o Egito africanamente cartografado gera incômodo nas pessoas - o qual é produzido por uma visão colonial imposta a nós. No Egito produziuse arte, ciência, tecnologia e filosofia, sendo uma África muito distante da fome, das epidemias e do retrato de pobreza que se produz discursivamente quando se fala em muitas mídias sobre esse território. Uma narrativa Eurocentrada estabeleceu a Grécia como berço da humanidade, apagando tudo que vinha do continente africano.

Tomaremos, então, como arcabouço teórico para análise Pinheiro (2020) e seu entendimento, com o qual corroboramos, do período das artes práticas como a química ancestral africana. A autora reitera que o surgimento da protoquímica, bem como o começo da humanidade, deu-se no continente africano e, a partir de uma leitura decolonial que se propõe a enfrentar o genocídio epistêmico do povo negro (NASCIMENTO, 2016), bem como a noção de pilhagem epistêmica (CÉSAIRE, 2006). A autora contribui para enfatizar a importância da abordagem - nas aulas que envolvam história da química dos conhecimentos químicos práticos e teóricos produzidos na África e entendê-los como pioneiros para todo o desenvolvimento posterior da Ciência que conhecemos como Química.

\section{O JOGO “ASSASSIN'S CREED ORIGINS”}

Assassin's Creed Origins é um jogo em terceira pessoa de ação e aventura que faz parte da franquia Assassin's Creed. Ele foi desenvolvido e publicado pela Ubisoft em 2017 para as plataformas PlayStation 4, XBOX One e $P C$, sendo um dos jogos mais aguardados daquele ano, o que refletiu em sua avaliação acima de 80 pontos no site Metacritic ${ }^{2}$. O enredo do game é ambientado no Antigo Egito e se passa em meados do ano 49 a.C. Como de costume na saga, sempre há um personagem que vive nos dias atuais que, através de um programa chamado Animus, visita memórias de um antepassado seu e assim as revive, trazendo conhecimento antigo para o presente. A personagem que carrega esse papel no game, Layla Hassan, é uma funcionária da Abstergo (empresa fundadora do programa Animus) que está insatisfeita com a empresa e tenta ganhar destaque por conta própria. Para isso, improvisa instalações do Animus em uma tumba egípcia e, assim, revive os passos de Bayek de Siuá personagem principal do jogo. Dando-se início ao gameplay, após algumas lutas e exploração de tumbas e ruínas com muitos tesouros, são apresentadas as novas mecânicas do jogo e nos é ensinado a controlar o personagem. A campanha de Assassin's Creed Origins, sem contar com as expansões lançadas posteriormente, dura aproximadamente 25 horas, enquanto para os jogadores que buscam completar $100 \%$ do jogo, pode levar até o dobro de tempo. O mapa do Egito fornece uma vasta exploração com muitos objetivos opcionais a serem feitos e lugares a serem descobertos. Para as unidades compradas no Brasil, o jogo vem totalmente dublado em português.

Segundo Marques e Rousso (2018), houve uma evolução da representatividade do povo egípcio e sua cultura ao longo dos anos no mundo dos vídeos games. Para os autores, jogos mais antigos, que de alguma forma giravam em torno do Egito, representavam de maneira simplista ou errônea o povo egípcio. Em Tomb Raider: The Last Revelation, por exemplo, jogo lançado em 1999, a protagonista explora o Egito durante toda sua jornada, porém, o único traço cultural trazido ao game é o despertar de um deus egípcio que poderia trazer destruição ao mundo. Além deste elemento, o jogo peca na representação de toda a civilização ao mostrar locais de exploração repetitivos cheios de múmias e pinturas nas paredes. Assim, mesmo que todo o jogo gire em torno do Egito Antigo, não há estímulo ou incentivo à curiosidade dos jogadores por esta cultura, servindo assim apenas como pano de fundo para o desenrolar da trama de uma personagem europeia.

2 Disponível em: <https://www.metacritic.com/game/pc/assassins-creed-origins> Acesso em: 19 de jun. de 2020. 
Entre Tomb Raider: The Last Revelation e Assassin's Creed Origins se passaram 18 anos e muitos jogos voltados para o Egito foram lançados ao longo desse tempo. Embora seja notável o crescimento da representatividade da civilização egípcia, isso não significou que houve uma preocupação cultural que poderia ter aparecido nos jogos lançados até meados de 2010, o que é bem diferente nos jogos atuais. Nas produções mais antigas, o Egito era sempre visto como um lugar que reproduz algum mal a ser combatido pelo protagonista, como nos exemplos citados anteriormente, com objetos que não pertenciam à época e má ambientação de cenário.

Por outro lado, em Assassin's Creed Origins, temos exatamente elementos opostos ao que já foi visto, com um protagonista egípcio, em um Egito bem ambientado, construído com base no estudo de historiadores e outros especialistas na área. Além disso, o jogo dentro de sua trama é o mais próximo possível dos fatos reais, trazendo personagens como Júlio César e Cleópatra, que diferente da maneira que é vista em muitos filmes e jogos já feitos, foi apresentada como uma mulher negra. Um fato curioso é que o jogo explica a origem de um credo secreto na África que futuramente combaterá uma enorme ordem liderada por europeus.

No modo turismo, ferramenta implantada no jogo, o jogador pode viajar por diferentes áreas do Egito enquanto um narrador conta toda a história do local. Citamos como exemplo a possibilidade de viajar até uma mina de natrão, construída virtualmente no jogo e inspirada em dados históricos. Enquanto o personagem caminha, pode-se ver figuras, instrumentos e diversos itens relacionados ao assunto em fotografias tiradas em museus que foram publicadas no jogo. Além disso, há um narrador que lê o texto exibido na tela para quem está jogando.

Para Mendes e Morais (2019), fica evidente que o modo turismo não tem como único objetivo o entretenimento, mas também instigar o jogador a conhecer sobre o contexto do jogo. $\mathrm{O}$ que não significa que esse faça uma reconstrução da época, mas sim que potencialize o aprendizado a partir da imersão proporcionada:

Os desenvolvedores mostram informações baseadas em pesquisas, mas não discutem suas fontes: provavelmente essa não seja a proposta do jogo em si. Aparentemente, não querem que o jogo seja apenas um retrato de uma época passada, mas que também ele apresente informações construtivas sobre essa época aos jogadores" (MENDES; MORAIS, 2019, p. 7).

O jogo não retrata uma verdade absoluta sobre o Egito, mas uma representação sobre ele, revelando conhecimentos compilados ao longo do tempo em respeito à antiga civilização, mas selecionados pelos desenvolvedores do jogo. Assim, o que buscamos é entender se tal orientação ideológica sobre ciência, ou sua representação de ciência, contribui para uma divulgação de ciência baseada em matrizes epistemológicas.

\section{PERCURSO METODOLÓGICO}

Com o objetivo de responder à questão de investigação apresentada no início deste artigo, desenvolvemos uma pesquisa documental (SÁ-SILVA; ALMEIDA; GUINDANI, 2009) com a análise de conteúdo (MORAES, 1999) como estratégia de análise. Segundo Appolinário (2011), documento pode ser entendido como "Qualquer suporte que contenha informação registrada, formando uma unidade, que possa servir para consulta, estudo ou prova. Incluem-se nesse universo os impressos, os manuscritos, os registros audiovisuais e sonoros, as imagens, entre outros" (p.67). Tendo como base esse conceito, entendemos o repositório de textos, imagens e sons disponibilizado pelo modo turismo de Assassin's Creed Origins como documentos relevantes para nossa investigação. Destacamos também que nossa análise foca nos elementos textuais, ou seja, não nos aprofundamos na análise dos recursos imagéticos utilizados pelos desenvolvedores. Esses elementos textuais foram analisados pela técnica de Análise do Conteúdo.

Para Moraes (1999), os dados chegam ao pesquisador em estado bruto, e cabe a ele realizar uma análise qualitativa, processar todo o conteúdo e separá-lo de forma que facilite sua leitura e que instigue o leitor a ter uma compreensão maior sobre o assunto abordado, obtendo uma interpretação mais coesa e que possa ler o texto de forma mais prática, indo direto para a parte que lhe interesse. 
O método utilizado para tal análise se baseia nas seguintes etapas:

1- preparação das informações: essa primeira etapa é responsável por submeter os conhecimentos ao início de uma codificação, separando-os em temas;

2- unitarização: nesse estágio, os códigos precisam ser criados de forma que os temas sejam formados por uma unidade/característica que os especifique, por exemplo: se um documento recebe o código $\mathrm{X}$, diferentes unidades de conteúdo similares a esse documento, ou seja, com assuntos parecidos também terão um código iniciado por $\mathrm{X}$, como $\mathrm{X}_{1}, \mathrm{X}_{2}$;

3- categorização: chegado a esse ponto, deve-se ter uma redução dos dados, em que somente os aspectos mais importantes prevalecem, ou seja, pode-se dizer que a terceira fase é como uma unitarização, porém, mais restrita, eliminando aspectos superficiais e exaltando as informações de valor;

4- descrição: a parte descritiva da análise tem como objetivo a organização de tabelas e quadros que apresentem as categorias presentes na análise e computando as frequências e percentuais presentes nestas. Por se tratar de uma análise qualitativa, a descrição tem como objetivo produzir um texto síntese para cada categoria que evidencie os significados presentes para as diversas categorias.

5- interpretação: por fim, a última parte da análise consiste em atingir um nível mais alto de compreensão, que vá além da descrição da quarta etapa. Entre as vertentes possíveis de interpretação, nos baseamos em um entendimento teórico prévio baseado em Pinheiro (2020) e a concepção de química ancestral africana.

No que diz respeito à preparação das informações, a Figura 1 a seguir representa a interface do jogo Assassins Creed Origins a qual utilizamos como base para a seleção dos documentos que seriam relevantes para essa análise.

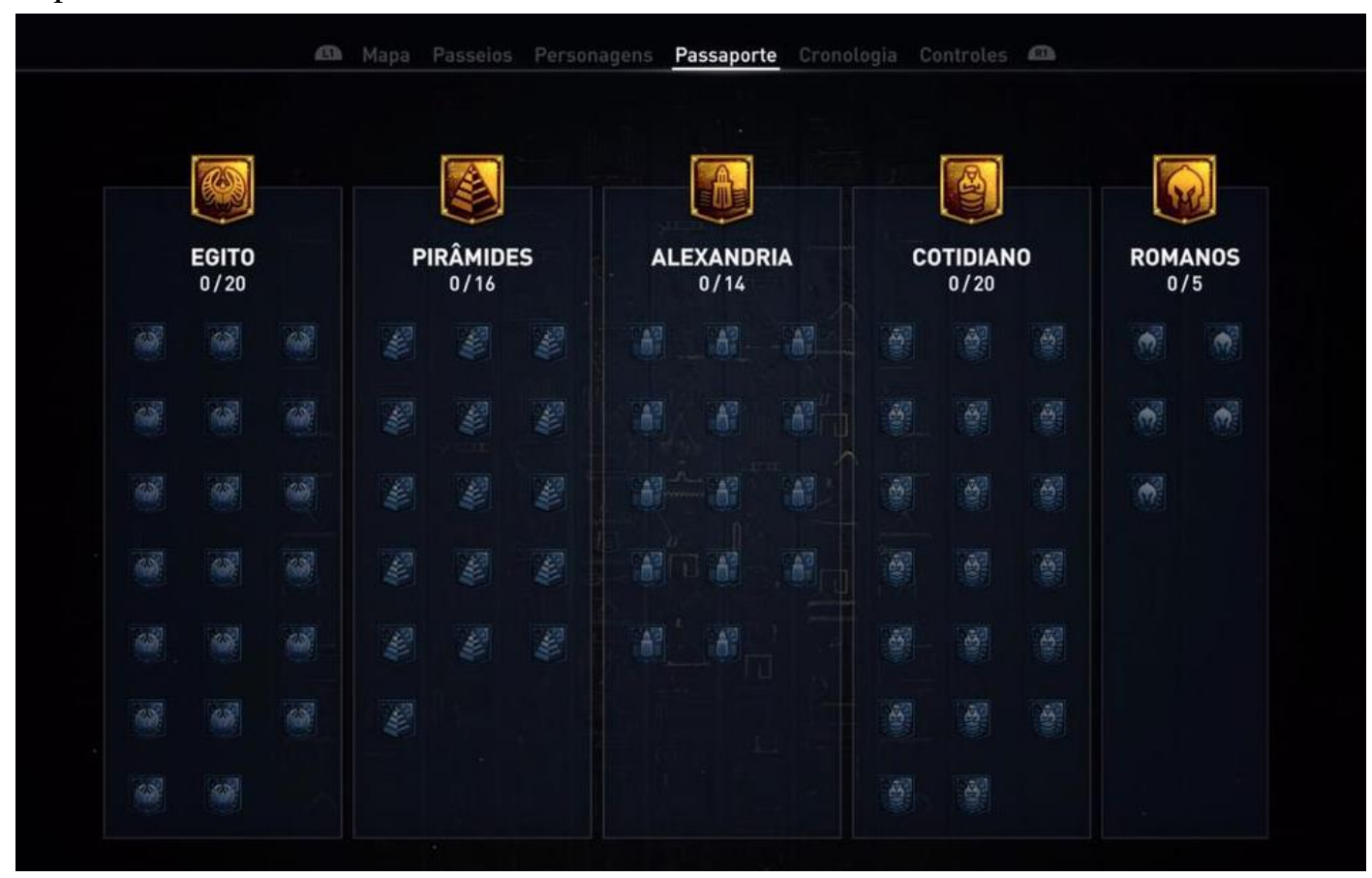

Figura 1 - Interface do modo turismo no jogo Assassin’s Creed Origins. Fonte: Dados da pesquisa.

A Figura 1 nos mostra que o item Egito possui 20 subitens; o item Pirâmides possui 16; Alexandria, 14; Cotidiano, 20; Romanos, 5. Cada subitem, para nosso objetivo de análise, foi nomeado a partir das letras iniciais do item seguido de um número crescente da esquerda para direita e de cima para baixo. E1, E2, E3, ..., E20; $\mathrm{P}_{1}, \ldots . \mathrm{P} 16 ; \mathrm{C}_{1}, \ldots, \mathrm{C}_{2} \mathrm{O} ; \mathrm{R} 1, \ldots, \mathrm{R}_{5}$.

Realizamos uma leitura de todos os textos disponíveis e assim, selecionamos aqueles relacionados a ciências da natureza. Em uma primeira leitura foi possível destacar a existência de conteúdos referentes ao que conhecemos hoje como "Q" -Química; "B" - Biologia; "Ar" - Arquitetura, "G" - Geografia, "Ag" -Agronomia. Com os textos escolhidos, um quadro com todos os conteúdos que 
o jogo possui foi elaborada, como uma espécie de sumário. Vale salientar que a construção do quadro foi realizada de maneira que ele fosse o mais semelhante possível ao quadro presente no jogo.

O Quadro 1 mostra uma ênfase em tais conhecimentos no tópico cotidiano, retratando as técnicas usadas no processo de mumificação. Assim, apareceram conhecimentos relacionados às áreas que hoje em dia consideramos como Química, Biologia, Arquitetura, Geografia e Agronomia. Como delimitação de nosso corpus de pesquisa, optamos por analisar os textos relacionados à Química. Assim destacaram-se os subitens E9, E11, E20, C1, C12, C16, C18, C19, C20.

Quadro 1: Representações das ciências que podem ser encontradas no modo turismo do jogo Assassin's Creed Origins.

\begin{tabular}{|c|c|c|c|c|}
\hline Egito & Pirâmides & Alexandria & Cotidiano & Romanos \\
\hline $\begin{array}{c}\text { E4: G } \\
\text { E9: Q } \\
\text { E11 :B; Q; G; Ag } \\
\text { E20: B; Q }\end{array}$ & - & $\mathrm{A}_{5}-\mathrm{Ar}$ & $\begin{array}{c}\text { C1: Q } \\
\text { C10: B; Ag } \\
\text { C12: B; Q } \\
\text { C16: Q } \\
\text { C18: Q } \\
\text { C19: Q } \\
\text { C20: Q; B }\end{array}$ & - \\
\hline
\end{tabular}

Fonte: Dados da pesquisa.

Em seguida, foi feita a etapa de unitarização, na qual utilizamos o código "letra" para designar o fragmento textual pertencente ao subitem - por exemplo: E9.A; E9.B, etc. Na etapa de categorização, após um trabalho de coleta de dados surgiram as categorias: 1) Ciência e Religião no Egito; 2) Geopolítica das matérias-primas; e 3) Conhecimentos, métodos e técnicas desenvolvidas no Egito.

\section{RESULTADOS E DISCUSSÃO}

Como foco de nosso trabalho e com objetivo de responder à nossa pergunta de investigação, escolhemos a categoria 3 na qual focamos nossa análise na apresentação dos resultados a seguir. Essa categoria possibilitou o surgimento das subcategorias 1 - Desenvolvimentos medicinais e cosméticos; 2 - Bebidas, alimentos e fabricação de produtos cotidianos; e 3 - Mumificação.

\section{Categoria: Conhecimentos, métodos e técnicas desenvolvidas no Egito}

Segundo Pinheiro (2020), a Química é a ciência que estuda a matéria, suas transformações e energias envolvidas. Ela surge, para a autora, a partir do momento em que o ser humano adquire domínio da manipulação técnica da matéria, ou seja, a compreensão sobre o domínio e capacidade de reprodução, a exemplo do fogo. Em muitos momentos da história o fogo era adquirido ocasionalmente - com um raio que parte uma árvore e provoca o início de um incêndio - porém, em um momento, o ser humano passa a dominar a produção desse fogo em um período denominado "artes práticas" e situado dentro da protoquímica.

A partir de uma leitura decolonial, que compartilhamos e concordamos com Pinheiro (2020), optamos por chamar tal período de "Química africana ancestral", de forma que tais conhecimentos adquirem status de ciência e sejam compreendidos em seus contextos de produção - no continente africano, mais especificamente em uma região denominada Egito e elaborados por negros e negras. 


\section{Subcategoria 1 - Desenvolvimentos medicinais e cosméticos.}

A subcategoria 1 refere-se aos desenvolvimentos medicinais e cosméticos. Pinheiro (2020) destaca que os seres humanos utilizam substâncias químicas com finalidades cosméticas, desde o início da pré-história (aproximadamente no ano 30.000 a.C.), com a utilização de corantes em rochas ou em pinturas corporais - e até mesmo em tatuagens. Segundo a autora "Posteriormente, outras aplicações e novos materiais foram desenvolvidos para maquiagens e produtos com potencial terapêutico, o objetivo era preservar a saúde e embelezar" (PINHEIRO, 2020, p.12).

Em Assassin's Creed Origins vários fragmentos textuais aparecem nos subitens Egito e cotidiano. Esses textos nos apresentam o povo egípcio dominando o uso de diferentes substâncias químicas para finalidades medicinais e cosméticas. Em C2o.B - "usavam óleo de mamona em lamparinas, mas também para cosméticos, como em tratamentos faciais e capilares" apresentam o óleo de mamona para aspectos estéticos, enquanto em C20.C "óleo de mamona [..] sendo prescrito para tratar constipação e ajudar mulheres grávidas” o mesmo material é utilizado para finalidades medicinais. Em E2o.B é retratada a extração de uma resina a partir das raízes de uma planta, o sílfio, para a produção de remédios que foram, posteriormente, usados por gregos e romanos: "As raízes do sílfio produziam uma resina usada por gregos e romanos em remédios feitos para curar tosse, febre, indigestão e tantas outras enfermidades. Também era usado como contraceptivo". Em C12.C é apresentada outra técnica medicinal: "Uma cura para a cegueira era feita com mel fermentado, ocra e Kohl”.

O domínio de técnicas para a resolução de problemas práticos, como, por exemplo, a extração de óleos, a mistura entre mel e ocra -argila amarelada - funcionando como o que hoje chamaríamos de uma mistura antisséptica e antibacteriana, bem como a capacidade analítica sobre os diferentes efeitos do óleo de mamona e o fato de que gregos e romanos utilizavam a resina das raízes de sílfio, são indícios tanto da potencialidade dos conhecimentos desenvolvidos nesse período, como o contato com gregos e romanos que viriam, posteriormente, a serem entendidos como "berço" do conhecimento científico. Esses são alguns dos fragmentos textuais, entre diversos outros, que contribuem para uma concepção de ciência ancestral africana, oriunda do Egito.

\section{Subcategoria 2 - Bebidas, alimentos e fabricação de produtos cotidianos}

A segunda subcategoria se refere a bebidas, alimentos e outros produtos cotidianos. Ao analisarmos os fragmentos textuais, foi possível perceber não apenas um grande domínio técnico, mas conceitos relacionados ao perecimento e a conservação dos alimentos. Exemplos disso são apresentados nos fragmentos: E9.A - "O natrão é um sal incolor que era usado pelos antigos egípcios para preservação de comida"; C19.C - "apenas alguns artesãos podiam fornecer os cascos necessários para armazenar e transportar vinho. Isso, e um controle de qualidade rigoroso estabelecido para cada etapa da produção de vinho" e C16.B - "Ela era usada em todos os aspectos da vida, do armazenamento de grãos e líquidos (...)" referindo-se à cerâmica.

Também fica evidente o conhecimento sobre separação de misturas, como destacado em E9.C no processo de extração do natrão, minério composto por principalmente sais de sódio (carbonato de sódio, bicarbonato de sódio, dentre outros) - "O natrão era extraído em Wadi al-Natrum. Os principais métodos de mineração envolviam a extração de placas do leito do lago quando esse estava seco, ou a evaporação da água saturada de mineral durantes as cheias".

Além dos aspectos relacionados à conservação dos alimentos, exemplificado pela utilização do natrão na salga de alimentos, o modo turismo de Assassin's Creed Origins permite que conheçamos um pouco sobre a origem da cerveja e o trato com o vinho. No que se refere à primeira, são abordadas a origem e a importância dos egípcios na sua produção, assim como a ênfase no domínio de processos como seleção de ingrediente, fermentação e conservação: C.18.D - "A receita mais básica usava cereal maltado como ingrediente principal. Também se usavam frutas como tâmaras, além de mel e especiarias"; C18.E - "Após a fermentação, o mosto da cerveja era transferido para contêineres grandes 
e prensado novamente, [...] Quando já não continha mais impurezas, a cerveja era armazenada em jarros de cerâmica com uma tampa de argila”.

Em relação ao vinho, tanto no âmbito do cultivo da uva quanto da produção e armazenamento: C19.B - "Uma tradição de milênios, o cultivo da uva e a produção de vinho eram regimentados de acordo com a típica burocracia do Egito Antigo. Os egípcios mantinham registros detalhados de vinicultores, identificados em rótulos". Tal fragmento dialoga com o que discutem Silva e Pinheiro (2018) sobre a produção de bebidas alcoólicas naquele contexto. Para as autoras, o desenvolvimento da sociedade egípcia foi de grande importância para o surgimento das bebidas alcoólicas, pois, no contexto de desenvolvimento do sedentarismo, foi possível que a agricultura e armazenamento de alimentos se desenvolvessem e, à medida que novos alimentos e bebidas eram consumidas, gerava-se processos de construção de conhecimento científico com intuito de suprir tal demanda.

Por fim, outro aspecto identificado no jogo se refere ao domínio dos egípcios no desenvolvimento e obtenção de diversos produtos cotidianos como nos trechos En1.A: "Possivelmente, a planta mais útil era o papiro. Esta variedade alta de junca crescia em abundância ao longo das margens do Nilo" e E11.B "Conhecida pelo seu uso como papel, os antigos egípcios a utilizavam para outras coisas, incluindo cordas, sandálias e tapetes..."

\section{Subcategoria 3 - Mumificação}

O modo turismo de Assassin's Creed Origins dá grande destaque ao processo de mumificação. Diversas etapas do processo são descritas, por exemplo, em E9.B - "Durante o ritual de embalsamento, os sacerdotes cobriam o corpo com natrão para desidratá-lo completamente", que é destacado um conhecimento sobre a desidratação dos corpos, processo que hoje, conceitualmente, conhecemos como osmose. Também estão presentem diversos indicativos de substâncias químicas presentes no processo:

C1.B - “[...] A purificação começava com uma libação de água sagrada. Então, os sacerdotes fumigavam o corpo com resina de terebinto. Após o ritual de limpeza, os sacerdotes usavam óleo, especiarias e essências para purificar ainda mais o corpo do defunto. Por fim, todos os pelos eram meticulosamente removidos. As partes restantes eram extraídas após um processo de liquefação realizado com o emprego de um líquido cáustico".

Assim, a purificação começaria com uma libação - processo que consiste em derramar um líquido sagrado em honra a um deus ou a uma entidade - e depois os sacerdotes fumigavam o corpo com a resina obtida de uma árvore, o terebinto, utilizariam, também, óleos e especiarias. Muito do desenvolvimento científico que o Egito proporcionou deriva de uma relação muito próxima entre ciência e religião.

Outros fragmentos textuais destacados reforçam o desenvolvimento, por exemplo, de uma ciência têxtil com o intuito de produzir materiais cada vez mais sofisticados para a mumificação: C1.G - "No fim, o corpo inteiro era enrolado com os membros ao lado do corpo, e técnicas de produção de faixas de linho cada vez mais sofisticadas e diferentes foram desenvolvidas". Referente a tais aspectos, Pinheiro (2020) reforça a imagem de ciência moderna, construída como um mito que se propõe a negar todos os conhecimentos produzidos anteriormente - a ciência moderna se apresenta como isenta de conhecimentos místicos, de base racional, empírica e assentada sobre a égide de uma neutralidade axiológica (PINHEIRO, 2020).

Conforme analisado acima, fica explícito que o povo egípcio tinha grande domínio do que consideramos hoje ciências da natureza, em especial da Química. Reforçamos que o jogo ajuda a enfrentar o mito criado sobre o eixo Greco-romano como berço do conhecimento, visto que nos diversos meios educacionais aprendemos sobre a Grécia e Roma como precursoras da matemática, química, geografia, filosofia, biologia, artes, literatura, medicina, história e muitas outras áreas do conhecimento.

Assim, a percepção das contribuições dos povos egípcios para o desenvolvimento científicotecnológico não descarta a importância da Europa para o desenvolvimento da humanidade, mas ajuda 
a enfrentar uma falsa sensação de que antes do conhecimento greco-romano o mundo passou por um longo hiato no qual não houve grandes acontecimentos de tamanha relevância para a ciência. Segundo Pinheiro (2020) uma breve leitura histórica basta para perceber que a civilização egípcia teve sua origem muito antes da grega e que a humanidade também é originária do continente africano. Como é possível imaginar que esses povos permaneceram improdutivos durantes milênios e só tiveram relevância histórica a partir do período escravagista?

Os egípcios desenvolveram inúmeras técnicas para aprimorar seu cotidiano e seus rituais. Um dos textos escritos expõe que, em um dos papiros escritos no Antigo Egito, há procedimentos médicos, produção de remédios e, em conjunto a eles, também estão prescritos poções, feitiços e rituais, evidenciando uma harmonia entre ciência e religião. Havia também uma grande prática de conservação da matéria desenvolvida a partir de processos de mumificação cada vez mais avançados e utilizando diferentes substâncias antissépticas. Foram desenvolvidas ferramentas para remoção de órgãos e preservação do corpo, além de um conhecimento avançado sobre fisiologia e anatomia humana. Tal conhecimento só se desenvolveu no continente europeu com o rompimento entre racionalidade e religião.

Outro aspecto a ser pontuado é a maneira como os egípcios tinham desenvolvido um controle de qualidade para seus alimentos, com uma grande supervisão durante toda a produção de vinhos, desenvolvimento de diversos filtros e peneiras para retirar areia e pedregulhos dos pães. Havia também medicamentos produzidos em decorrência da dor de dente ocasionada pelos grãos arenosos encontrados no pão, já que não existiam filtros com poros pequenos o suficiente para remover todas as impurezas encontradas no alimento.

Também vale ressaltar outros desenvolvimentos egípcios, como a cerâmica e o uso do papiro. A cerâmica, por exemplo, possuía várias utilidades que são similares até hoje como armazenamento de utensílios, comida e arte - os recipientes cerâmicos egípcios sempre continham alguma pintura, foram de suma importância para que arqueólogos(as) pudessem criar modelos sobre essa civilização.

A produção de cerveja, como já citada, também foi muito aprimorada durante o Império Egípcio, em conjunto à produção de pão. Os egípcios, além de conhecimentos químicos a respeito de fermentação, granulação e outros procedimentos, precisavam saber a respeito de agricultura, como preparo de solo, quando plantar e colher, saber como o tempo influenciava nas plantações, conhecimentos que são amplamente utilizados até os dias atuais. Havia também fornos nos quais eram assados os pães e aparatos criados para irrigar o solo de residências mais distantes do Nilo.

Contudo, mesmo com a produção de algumas cervejas egípcias na atualidade, os historiadores não foram capazes de reproduzir alguns sabores, pois havia ingredientes que foram extintos na época e não são mais encontrados, como o sílfio, uma planta de uso decorrente na fabricação de cosméticos e remédios e no emprego culinário. Mesmo assim os processos de fabricação de cerveja artesanal da atualidade ainda são muito similares aos da época.

Além disso, muito do que usufruímos hoje teve origem no Egito, como o desenvolvimento de peneiras para filtragem de resíduos, técnicas de irrigação e procedimentos na fabricação de alcoólicos. Apesar disso, diversos processos como Epistemicídios e Pilhagens epistêmicas, usurparam da África o direito ao reconhecimento e a colocaram em um espaço no qual as referências remontam a escravidão. Tal período não pode ser esquecido, para isso é importante que compreendamos o continente africano como produtor de ciência, tecnologia, berço de conhecimentos importantes para o desenvolvimento humano e consideramos que o jogo ACO, em seu modo turismo, contribui para tal entendimento.

\section{ALGUMAS CONSIDERAÇÕES}

Quando estabelecemos a pergunta se o jogo Assassin's Creed Origins, em seu modo turismo, apresentaria um conteúdo sobre Ciência Química que enfatizasse matrizes epistêmicas não europeias, levantamos a hipótese que sim, devido à aparente potencialidade do jogo em abordar questões históricas e científicas. E, durante a análise, confirmamos tal hipótese. 
A análise do conteúdo proporcionou que surgisse uma categoria que fosse relevante para esse trabalho, intitulada "Conhecimentos, métodos e técnicas desenvolvidas no Egito" a qual possibilitou o surgimento de três subcategorias, sendo elas "Desenvolvimentos medicinais e cosméticos"; "Bebidas, alimentos e fabricação de produtos cotidianos" e "Mumificação". O desenvolvimento das subcategorias apresentadas nos fez entender que, no modo turismo, há diversos fragmentos textuais que relacionam o contexto do jogo aos conhecimentos relacionados à química - em específico ao que Pinheiro (2020) chama de Química Ancestral Africana.

Tais conhecimentos, marginalizados em aulas de Química, bem como aulas de História da Química do Ensino Superior, estão disponíveis no jogo. O fato de o conteúdo do modo turismo de Assassin's Creed Origins corroborar com a apresentação de uma Química Ancestral Africana, bastante detalhada, permite aos professores(as) que tenham acesso a um material rico o qual contribui para ampliar concepções sobre a Ciência, principalmente no que diz respeito às suas origens.

Retratar a Ciência Química com mais "berços" do que a Grécia não apaga a importância dos conhecimentos gregos, pois os mesmos se somam e proporcionam questionamentos. As perguntas, talvez, coloquem dúvida no imaginário de reinado absoluto da Grécia, podendo suscitar indagações sobre "como a Europa conseguiu fazer com que surgisse tantos conhecimentos e em tantas áreas distintas?"

A resposta para tais dúvidas está no entendimento de processos como epistemicídio e pilhagens epistêmicas. Reconhecê-los ressoa com o princípio de educar para nunca mais. Reconhecer as violências praticadas, as violações de direitos e explicitá-las para que lembremos, constantemente, e não corramos o risco de repetir erros do passado. Os jogos digitais estão presentes na vida de crianças, jovens e adultos. Os elementos que os compõem - música, texto, narrativa, motor, etc. podem ser aliados de professores(as) e divulgadores(as) de ciência, cabendo a nós, decidirmos de que modo queremos que os games sejam nossos aliados, assim como já fazemos com vídeos, músicas, e tantas outras formas de arte.

\section{REFERÊNCIAS}

APPOLINÁRIO, F. Dicionário de metodologia científica: um guia para a produção do conhecimento científico. São Paulo/Brasil: Editora Atlas, 2011.

CÉSAIRE, A. Discurso sobre el colonialismo. Madrid/Espanha: Ediciones Akal, 2006.

CLEOPHAS, M. G., \& Cavalcanti, E. L. D., \& Soares, M. H. F. Afinal de contas, é jogo educativo, didático ou pedagógico no ensino de química/ciências? Colocando os pingos nos "is". In. CLEOPHAS, M. G., \& SOARES, M. H. F. (Orgs.), Didatizacão Lúdica no Ensino de Química/ciências: teorias de aprendizagem e outras interfaces. São Paulo: Editora Livraria da Física, p. 33-43, 2018.

COSTIKYAN, G. I have no words I must design: Toward a critical vocabulary for games. In: Proceedings of Computer Games and Digital Cultures. Conference,New York/USA: Tampere University Press, 2020.

DUBIELA, R. P.; BATTAIOLA, A. L. A importância das Narrativas em jogos de Computador. in: Proceeding of the Brazilian Symposium on Games and Digital Entertainment, 2007.

FLANAGAN, M. Critical Play: Radical Game Design. Academy of Art University: The MIT Press, 2009.

GROSFOGUEL, R. A estrutura do conhecimento nas universidades ocidentalizadas: racismo/sexismo epistêmico e os quatro genocídios/epistemicídios do longo século XVI. Sociedade e Estado, v. 31, n. 1,, p. 25-49. 2016.

CASTRO-GÓMEZ, S.; GROSFOGUEL, R. Reflexiones para una diversidad epistémica más allá del capitalismo global. Bogotá: Siglo del hombre editores, 2007.

JASPERS, K. Ciência e verdade (tradução de Antônio Abranches). O que nos faz pensar, [S.l.], v. 1, n. 1, p. 104117, 1989. 
KELLNER, D. A cultura da mídia: estudos culturais, identidade, e política entre o moderno e pósmoderno. Bauru/São Paulo: EDUSC, 2001.

LANDER, E. Ciências sociais: saberes coloniais e eurocêntricos. A colonialidade do saber:

eurocentrismo e ciências sociais. Perspectivas latino-americanas. Buenos Aires/Argentina: CLACSO, p.

21-53, 2005.

MALDONADO-TORRES, N. Sobre la colonialidad del ser: contribuciones al desarrollo de un concepto. El giro decolonial. Reflexiones para una diversidad epistémica más allá del capitalismo global, p. 127-167, 2007.

MALDONADO-TORRES, N. Del mito de la democracia racial a la descolonización del poder, del ser, y del conocer, 2007. Documento multicopiado. Disponível em:

<https://globalstudies.trinity.duke.edu/sites/globalstudies.trinity.duke.edu/files/file-

attachments/DelMito.pdf>. Acesso em: 13 de jun. de 2020.

MARQUES, F.; ROUSSO, I. Nota crítica à representação cultural do Antigo Egito nos jogos eletrônicos. In: SBGames. Rio de Janeiro, RJ, 2018.

MENDES, J.; MORAIS, M. Múmias digitais: práticas funerárias em Assassin's Creed Origins. ARISE Arqueologia interativa de Simulações Eletrônicas (MAE/USP), 2019.

MIGNOLO, W. Desobediência epistêmica: a opção descolonial e o significado de identidade em política. Cadernos de Letras da UFF-Dossiê: Literatura, língua e identidade, 34, p. 287-324, 2008. MIGNOLO, W. Histórias locais/projetos globais: colonialidade, saberes subalternos e pensamento liminar. Belo Horizonte: Editora UFMG, 2003.

MIRANDA, C. (2013). Currículos decoloniais e outras cartografias para a educação das relações étnico-raciais: desafios político-pedagógicos frente à Lei no 10.639/2003. Revista da Associação Brasileira de Pesquisadores/as Negros/as (ABPN), 5(11), p. 100-118, 2013.

MORAES, R. Análise de conteúdo. Revista Educação, Porto Alegre, 22(37), p. 7-32, 1999.

NASCIMENTO, A. O genocídio do negro brasileiro: processo de um racismo mascarado. São Paulo/SP: Perspectivas, 2016.

OLIVEIRA, R. D. V. L.; SALGADO, S. D. C. A Educação em Direitos Humanos no Ensino de Ciências em interface com a teoria do Giro Decolonial: uma análise. Ensino em Re-Vista, v. 27, n. 2, p. 698-726, 2020.

OLIVEIRA, R. D. V. L..; SILVA, J. R. R. T. Jogos digitais como arte na interface entre educação científica e educação em direitos humanos: reflexões e possibilidades. Revista Eletrônica Ludus Scientiae, Foz do Iguaçu, v. 03, n. 02, p. 12-34, 2019.

PINHEIRO, B. C. S. O período das artes práticas: a química ancestral africana. Revista Debates em Ensino de Química (REDEQUIM), 6(2) p. 4-15, 2020.

PINHEIRO, B. C. S; OLIVEIRA, R. D. V. L. Divulgação... De qual ciência? Diálogos com epistemologias emergentes. In ROCHA, M. B., \& OLIVEIRA, R.D.V.L. (Orgs.), Divulgação científica: textos e contextos. São Paulo: Editora Livraria da Física, 2019. p. 1-11.

PINHEIRO, B. C. S; ROSA, K. Descolonizando saberes a lei 10.639/2003 no ensino de ciências. São Paulo, Livraria da Física, 2018.

QUIJANO, A. Colonialidade do poder, Eurocentrismo e América Latina. In: A colonialidade do saber: eurocentrismo e ciências sociais. Perspectivas latino-americanas. Buenos Aires: CLACSO, Consejo Latinoamericano de Ciencias Sociales, p. 117-142, 2005.

SANTOS, B. D. S., \& MENESES, M. P. Colonialidade do Poder e classificação social-Aníbal Quijano. In SANTOS, Boaventura de Souza. Epistemologia do Sul. 2ª ed. Coimbra: Almedina, p. 73-113, 2013.

RANCIÈRE, J. Entrevista a Flávia Natércia. Ciência e Cultura, 57, 2005· p. 16-17.

RICHTER, I. M. Arte-Educação Intercultural: pensando a realidade brasileira. Pedagogia da arte: entrelugares da criação. Rio Grande do Sul, Editora UFRGS, 2010.

SÁ-SILVA, J. R.; ALMEIDA, C. D. D.; GUINDANI, J. F. Pesquisa documental: pistas teóricas e metodológicas. Revista brasileira de história \& ciências sociais, 1(1), 2009. p. 1-15.

SILVA, A. H.; FOSSÁ, M. I. T. Análise de conteúdo: exemplo de aplicação da técnica para análise de dados qualitativos. Qualitas Revista Eletrônica, 16(1), 2015. 
SILVA, E. M.; ARAUJO, C. M. D. Tendências e concepções do ensino de arte na educação escolar brasileira: um estudo a partir da trajetória histórica e socioepistemológica da arte/educação. REUNIÃO DA ANPED, 30, 2007.

SILVA, L. H.; PINHEIRO, B.C.S. Produções Científicas no antigo Egito: um diálogo sobre Química, Cerveja, Negritude e outras coisas mais. Revista Debates em Ensino de Química (REDEQUIM), v. 4, n. 1, p. 5-28, 2018.

Roberto Dalmo Varallo Lima de Oliveira: Licenciado em Química pela Universidade Federal Fluminense (2012), Mestre e Doutor em Ciência, Tecnologia e Educação pelo CEFET-RJ (2017). Foi professor da Escola Básica. Trabalhou entre 2014 e 2017 na Universidade Federal do Tocantins (UFT), entre 2017 e 2019 na Universidade Federal de Uberlândia (UFU). Atualmente, é professor da Universidade Federal do Paraná (UFPR). Editor da seção Debates em Direitos Humanos, Culturas e Justiça Social no Ensino de Química da Revista REDEQUIM. Um dos coordenadores da Coleção "Culturas, Direitos Humanos e Diversidades na Educação em Ciências”. Nos últimos anos começou a se dedicar aos estudos sobre Jogos Digitais e sua relação com a Educação Científica e Tecnológica. É membro do GEECCplay (Grupo de Estudos em Educação Científica e Critical Play).

E-mail: robertodalmo7@gmail.com

Vinícius Gurski Ferraz: É Técnico em Química pelo SENAI, Licenciando em Química pela Universidade Federal do Paraná, membro do projeto de Ensino PIBID (programa de Bolsas de Iniciação à Docência), membro do GEECCplay (Grupo de Estudos em Educação Científica e Critical Play). Estuda a os jogos digitais no contexto da Educação Científica e Tecnológica.

E-mail: vinigurskiferraz@gmail.com

João Roberto Ratis Tenório da Silva: Docente da Universidade Federal de Pernambuco (UFPE), no Centro Acadêmico do Agreste, Núcleo de Formação Docente e professor permanente do Programa pós-graduação em Educação em Ciências e Matemática (PPGECM/UFPE). Licenciado em Química e Mestre em Ensino das Ciências pela Universidade Federal Rural de Pernambuco (UFRPE) e doutor em Psicologia Cognitiva pela Universidade Federal de Pernambuco (UFPE), tendo sido bolsista CAPES do Programa de DoutoradoSanduíche no Exterior (PDSE) durante cinco meses no Niels Bohr Centro de Psicologia Cultural Universidade de Aalborg, Dinamarca. Tem experiência na área de Ensino de Química, com ênfase no processo de ensino e aprendizagem e formação de conceitos. Vem atuando, principalmente, em temas que envolvem: perfil conceitual, elaboração de jogos digitais e analógicos para o ensino de ciências e relações entre memória, imaginação e aprendizagem. Editor da Revista Debates em Ensino de Química. Membro do GEECCplay (Grupo de Estudos em Educação Científica e Critical Play)

E-mail: joaoratistenorio@gmail.com

Mayara Soares de Melo: Licenciada em Química (UnB), Mestra em Ensino de Ciências (PPGEC/UnB) e doutoranda em Educação em Ciências (PPGEduC/UnB). Professora do Centro das Ciências Exatas e das Tecnologias da Universidade Federal do Oeste da Bahia (CCET/UFOB) com atuação na área de ensino de Ciências/Química. Foi professora do ensino médio regular no Distrito Federal e atuou no ensino médio integrado no Instituto Federal. Desenvolve pesquisas sobre divulgação científica, formação de conceitos científicos e educação científica e direitos humanos. Participa do projeto Caminhão da Ciência (UFOB). Membro do GEECCPlay (Grupo de Estudos em Educação Científica e Critical Play) e do Grupo Diálogos FormAtivos em Educação em Ciências (UFOB).

E-mail: mayara.melo@ufob.edu.br 